\title{
Vesical Teratoma: A Rare Case Presentation
}

\section{Narayan Thapa, Bikash Bikram Thapa, Bharat Bahadur Bhandari and Bhairab Kumar Hamal}

Department of Surgery, Nepalese Army Institute of Health Sciences, Shree Birendra Hospital, Kathmandu, nepal.

\begin{abstract}
Dermoid cysts are extremely rare in the urinary bladder and pose a diagnostic dilemma to both the Urologist and the Histopathologist. Only a few cases were found documented and published in literature. We present a case of dermoid cyst in the urinary bladder presenting as a bladder mass which is very rare tumour. Diagnosis of this case was made cystoscopically and confirmed by histopathologically. Complete excision of mass was possible by endoscopic resection.
\end{abstract}

Keywords: dermoid tumor; urinary bladder; surgery

\section{INTRODUCTION}

Dermoid cysts are benign 'tumours', which are considered as developmental anomalies. They occur most commonly in the ovaries but may also be found at other sites, especially in the midline and para-axial locations. They are rare in the urinary bladder. We present a case of dermoid cyst in the urinary bladder of a 45-year old woman associated with diverticulum which is very rare tumour in the urinary bladder.

\section{CASE REPORT}

A 45-year-old woman presented with a 2-year history of lower urinary tract symptoms (LUTS) characterized by frequency, nocturia, urgency, and dysuria. There was occasional haematuria but no history of obstructive lower urinary tract symptoms or weight loss. She was house wife by profession. On examination her general condition and systemic examination were within normal limits. Her all basic investigations were also within normal limit. An abdominopelvic ultrasound scan revealed that the upper urinary tract was normal, with a solid mass located at the posterior wall of urinary bladder. On urethrocystoscopy, a single bladder mass presented in the posterior midline of the bladder, with evidence of surrounding cystitis which was white in colour with broad base and associated with bladder diverticulum, rest of the urinary bladder was normal.

She received one course of antibiotics for cultureproven klebsiela urinary tract infection preoperatively. With provisional diagnosis of bladder mass we planned for TURBT; the mass was resected including $1 \mathrm{~cm}$ margin. Intra operative finding were grey brown mass of about $3 / 4 \mathrm{~cm}$, firm in consistency containing hair follicles and some calcify structure. On histopathological report, mass consisting of stratified squamous epithelium, with adnexial structures including sweat glands and hair follicles. After surgery and histopathological report our final diagnosis was urinary bladder dermoid tumour. We asked patient to come in regular follow up based on international protocol. During the period of one year follow up there is no evidence of recurrence and no feature of dermoid in other site of the abdomen detected by ultrasound and CECT scan of abdomen.

\section{DISCUSSION}

Midline teratomas presumably result from abnormal germ cells. A dermoid cyst in the urinary bladder is an extremely rare 'tumour'. We found only few cases reported and published in the literature. Misra $\mathrm{S}$ et al presented a case of dermoid tumour in 8 years old girls. They usually contain
This work is licensed under: http:// creativecommons.org/licenses/by-nc-nd/4.0/

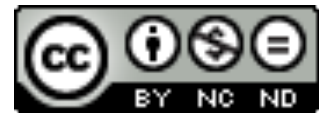

Correspondence: Narayan Thapa, Department of Surgery, Nepalese Army Institute of Health Sciences, Shree Birendra Hospital, Kathmandu, Nepal.

Email: snthapa2061@gmail.com 


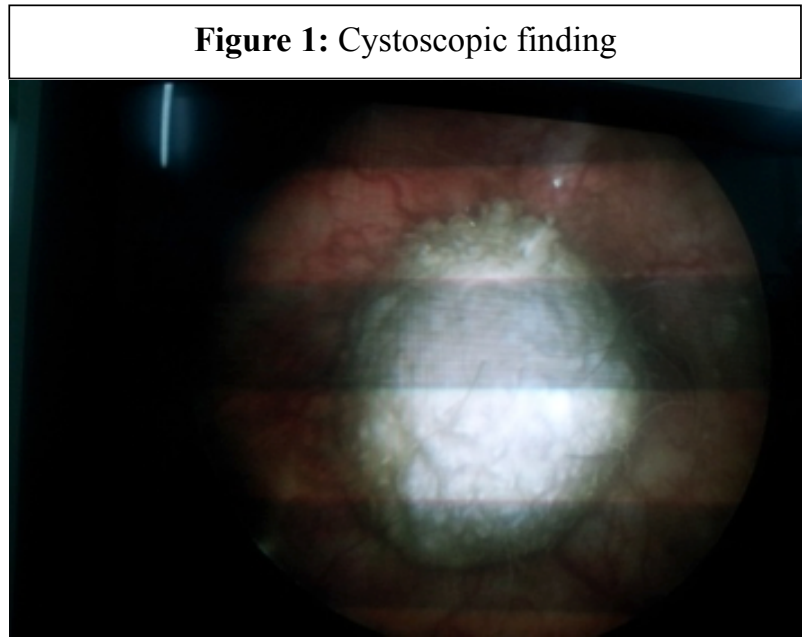

Figure 2: Intraoperative finding showing hair within tumor

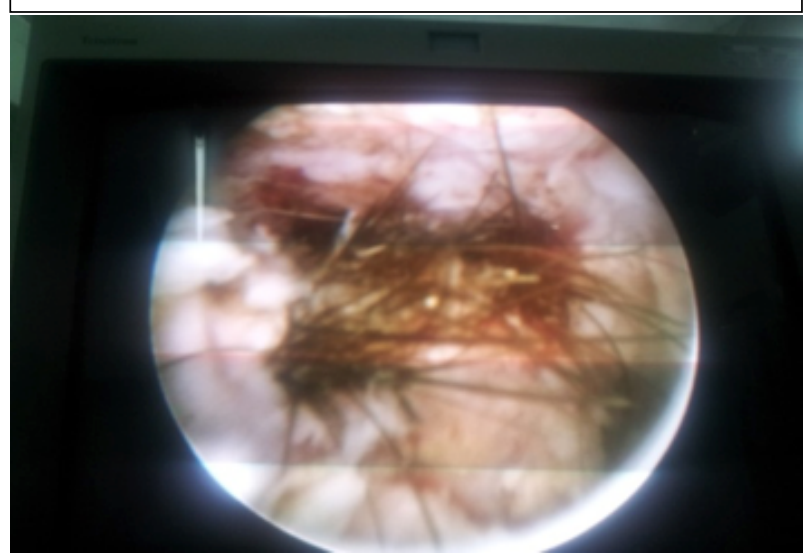

Figure 3: Resected specimens showing some calcified tissue

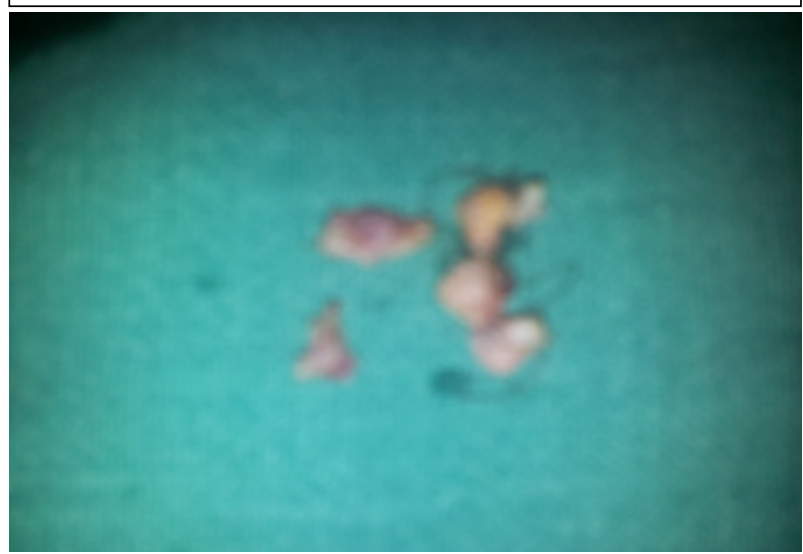

hair and calcified material. It may also be associated with bladder diverticulitis and vesical stones. A case presented by Lazebnik $\mathrm{J}$ et al, where vesical teratoma was associated with bladder stone and diverticulum. In our case, a solitary tumour located in the posterior wall of the bladder in the midline. It contained calcified material and hair follicles. The position of the bladder mass in this patient and Histopathological report was suggestive of a dermoid tumour. Linus okeke et al, presented a case of dermoid tumour in the urinary bladder presented with feature of bladder stone. This type of case does not reported in Nepal and this may be the first case presented here.

\section{CONCLUSIONS}

Dermoid tumour in the urinary bladder is extremely rare presentation, but it should be taken as differential diagnosis of bladder mass. The patient as well as the surgeon can be reassured since it is benign and will not need further treatment.

\section{REFERENCES}

1. Misra S, Agarwal PK, Tandon RK, Wakhlu AK, Misra NC. Bladder teratoma: a case report and review of literature. Indian J Cancer.1997;34:20-21.

2. Kumar V, Abass AK, Fausto N, editor. Robbins pathologic basis of disease. 7. Philadelphia: Saunders, Elsevier; 2004. pp. 1099-1104.

3. Agrawal S, Khurana N, Mandhani A, Agrawal V, Jain M. Primary bladder dermoid: a case report and review of the literature. Urol Int. 2006;77:279-80. doi: 10.1159/000094823.

4. Lazebnik J, Kamhi D. A case of vesical teratoma associated with vesical stones and diverticulum. J Urol. 1961;85:796-799.

5. Linus I Okeke, Gabriel O Ogun, Blessing R Etukakpan et al, Dermoid cyst of the urinary bladder as a differential diagnosis of bladder calculus. J Med. 2007 june 26, 1:32. 